\title{
Complete genome and sequence and phylogenetic analyses of the first bovine norovirus strain identified in northern China
}

\author{
Meng-Jia Wang ${ }^{1}$, Jinghui Fan ${ }^{2}$, Hui-Xia Fan ${ }^{1}$, Ying Liu ${ }^{1}$, Zhi-Hao Peng ${ }^{1}$, Yu-Zhong Ma ${ }^{1}$, \\ Qing-Yan $\mathrm{Li}^{1}$, and Yu-Zhu Zuo ${ }^{1}$
}

${ }^{1}$ Affiliation not available

${ }^{2}$ Hebei Agricultural University

April 28, 2020

\begin{abstract}
Bovine norovirus $(\mathrm{BNoV})$ is a recently identified calicivirus in the genus Norovirus, which can cause enteric disease with clinical signs including vomiting, diarrhea, dehydration, and mortality in neonatal calves. BNoV has been reported in different countries all over the world. We collected 39 fecal, blood, and tissue samples from calves with diarrhea from Hebei in northern China in 2019. The presence of BNoV was determined by PCR only two samples (5.1\%) were positive. The complete genome of the newly identified strain Bo/CH/HB/BD/2019 was successfully sequenced (GenBank accession number: MN480761). Based on the existing gene sequences in the GenBank database, evolutionary trees were constructed. Sequence analysis showed that the nucleotide sequence homology of the Bo/CH/HB/BD/2019 genome with BNoV genomes in GenBank was 84.0-92.4\%. $\mathrm{Bo} / \mathrm{CH} / \mathrm{HB} / \mathrm{BD} / 2019$ has a GIII.2 genotype, and further analysis of its VP1 gene revealed four amino acid substitutions, i.e., $225 \mathrm{C}, 246 \mathrm{~T}, 624 \mathrm{~T}$, and $945 \mathrm{~T}$. To the best of our knowledge, this is the first time the complete genome of a BNoV isolate from northern China has been sequenced.
\end{abstract}

Complete genome and sequence and phylogenetic analyses of the first bovine norovirus strain identified in northern China

Meng-Jia Wang ${ }^{\mathrm{a}, 1}$ https://orcid.org/0000-0003-2493-0723, Jing-Hui Fan ${ }^{\mathrm{a}, \mathrm{b}, 1}$, Hui-Xia Fan ${ }^{\mathrm{c}, 1}$, Ying Liu ${ }^{\mathrm{a}}$, ZhiHao Peng ${ }^{\mathrm{a}}$, Yu-Zhong Ma ${ }^{\mathrm{a}, \mathrm{b}}$, Qing-Yan $\mathrm{Li}^{\mathrm{a}}{ }^{\text {, }}$, Yu-Zhu Zuo ${ }^{\mathrm{a}, \mathrm{b}, *}$

${ }^{1}$ These authors contributed equally to this work.

${ }^{a}$ College of Veterinary Medicine, Hebei Agricultural University, Baoding 071001, People's Republic of China.

${ }^{\text {b} H e b e i ~ V e t e r i n a r y ~ B i o t e c h n o l o g y ~ I n n o v a t i o n ~ C e n t e r, ~ B a o d i n g ~ 071001, ~ P e o p l e ' s ~ R e p u b l i c ~ o f ~ C h i n a . ~}$

'Information science and technology, Hebei Agricultural University, Baoding 071001, People's Republic of China.

*Author for all correspondence: Qing-Yan Li; Yu-Zhu Zuo

Tel.: +86-312-7528581; fax: +86-312-7520275

E-mail address: zuoyuzhu@163.com (Yu-Zhu Zuo)

\section{Summary}

Bovine norovirus (BNoV) is a recently identified calicivirus in the genusNorovirus, which can cause enteric disease with clinical signs including vomiting, diarrhea, dehydration, and mortality in neonatal calves. $\mathrm{BNoV}$ has been reported in different countries all over the world. We collected 39 fecal, blood, and tissue 
samples from calves with diarrhea from Hebei in northern China in 2019. The presence of BNoV was determined by PCR only two samples $(5.1 \%)$ were positive. The complete genome of the newly identified strain $\mathrm{Bo} / \mathrm{CH} / \mathrm{HB} / \mathrm{BD} / 2019$ was successfully sequenced (GenBank accession number: MN480761). Based on the existing gene sequences in the GenBank database, evolutionary trees were constructed.

Sequence analysis showed that the nucleotide sequence homology of the Bo/CH/HB/BD/2019 genome with BNoV genomes in GenBank was 84.0-92.4\%. Bo/CH/HB/BD/2019 has a GIII.2 genotype, and further analysis of its VP1 gene revealed four amino acid substitutions, i.e., 225C, 246T, 624T, and 945T. To the best of our knowledge, this is the first time the complete genome of a $\mathrm{BNoV}$ isolate from northern China has been sequenced.

Keywords: Bovine norovirus, calf diarrhea, complete genome, genomic sequence, phylogenetic analysis

\section{Introduction}

Noroviruses (NoVs) are important pathogens causing gastroenteritis in children and young animals. Infection with $\mathrm{NoV}$ in children and young animals can cause intestinal lesions and post-infectious diarrhea (Smiley,Chang,Hayes,Vinje, \& Saif, 2002; Bridger,Hall, \& Brown, 1984; Woode \& Bridger, 1978). In humans, NoV is one of the most important etiological agents of gastroenteritis; however, little is known about NoV causing diarrhea in cattle.

NoVs are small non-enveloped, positive-sense single-stranded RNA viruses. According to the diversity of the VP1 amino acid (aa) sequence, NoVs are divided into seven genogroups (GI to GVII). Bovine NoVs (BNoVs) belong to GIII and are further divided into two different genotypes, i.e., genotype 1 (Bo/Jena/1980/DE) and genotype 2 (Bo/newbury2/1976/UK), which were first identified in Germany (Otto et al., 2011) and the UK (Jung,Scheuer,Zhang,Wang, \& Saif, 2014). The BNoV genome, which has a size of 7.5-7.7 kb, contains three open reading frames (ORFs). Starting from the 5' end of the genome, ORF1 encodes a non-structural protein, including an enzyme responsible for transcription, viral genome replication, and accurate initiation of RNA synthesis by RNA-dependent RNA polymerase (RdRp). RdRp prevents the virus from losing its genetic information (Deval,Jin,Chuang, \& Kao, 2017; Lee,Chung, \& Kim, 2017). ORF2 encodes the major capsid protein VP1 . It is involved in receptor recognition and host specificity (Chen et al., 2004).Viral evasion of antibody neutralization results in frequent variations in the VP1 aa sequences, which are also associated with the emergence of new epidemic strains (Lochridge \& Hardy, 2007; Lindesmith et al., 2013). ORF3 encodes the minor capsid protein VP2 , a hypervariable protein that may play a role in maintaining the stability of NoV particles (Lin,Fengling,Lianzhu,Yuxiu, \& Yanhua, 2014).

Previous studies have reported the detection of BNoV in many countries including the UK (Woode \& Bridger, 1978; Bridger,Hall, \& Brown, 1984), Germany (Gunther,Otto, \& Heilmann, 1984), the Netherlands (van der Poel et al., 2003; van Der Poel et al., 2000), the USA (Cho et al., 2013; Wise et al., 2004), New Zealand (Wolf et al., 2007), South Korea (Park et al., 2007), Norway (Jor,Myrmel, \& Jonassen, 2010), France (Kaplon,Guenau,Asdrubal,Pothier, \& Ambert-Balay, 2011), Turkey (Kaplon,Guenau,Asdrubal,Pothier, \& Ambert-Balay, 2011), and Tunisia (Hassine-Zaafrane et al., 2012). According to previous reports, BNoV was first detected in Southern China in 2018 (Wang,Yue, \& Tang, 2019), and it was detected in central China in 2019 (Shi,Wang,Xu,Zhang, \& Lan, 2019).

$\mathrm{BNoV}$ has become a threat to the global cattle industry, and it may bring huge economic losses to the cattle industry in China. Although BNoV is prevalent globally, the study of its pathogenicity, epidemiology, and molecular biology is only in the preliminary stage. Up to now, GenBank contained only seven complete BNoV genome sequences; two are GIII.1 strains (GenBank accession numbers: MK159169 and AJ011099) and five are GIII.2 strains (GenBank accession numbers: JX145650, AY126474, AF097917, MN122335.1, and EU794907). In China, only two BNoV genomes have been completely sequenced, i.e., one from southern China and one from central China. There are not enough data to establish the genetic relationship and evolutionary rate of BNoVs in China. At present, the virus has not been successfully isolated, hindering the development of an effective vaccine. We studied the molecular profile of the virus and analyzed its genetic variation, in order to provide a reference for the prevention and control of viral spread in China. 
We identified a $\mathrm{BNoV}$ strain, named Bo/CH/HB/BD/2019, from Hebei, in northern China, and conducted phylogenetic analysis of the entire genome and the VP1 region. BNoV may be highly prevalent in China, but there are few epidemiological data on the prevalence of the virus. This study lays a foundation for the further exploration of the molecular biological characteristics of BNoV and the prevalence of BNoV in China.

\section{Materials and methods}

\section{Sample information}

Between April 2019 and September 2019, we collected and analyzed 39 samples from five different farms with calf diarrhea in Hebei, China, including 30 diarrheal fecal samples, 5 blood samples and 4 tissue samples (lung, liver, kidney, heart). Samples were screened for BNoV by nested PCR.

\section{Nucleotide extraction and PCR detection of BNoV}

Total RNA was extracted by TRIzol reagent following the manufacturer's instructions (Invitrogen, Carlsbad, CA, USA). Reverse transcription was performed using the PrimeScript ${ }^{\mathrm{TM}} 1$ st strand cDNA Synthesis Kit (TaKaRa Biotechnology, Dalian, China) with an oligo dT primer. Nested PCR primers (F, AGTTAYTTTTCCTTYTAYGGBGA; R, AGTGTCTCTGTCAGTCATCTTCAT (Smiley,Hoet, Traven, Tsunemitsu, \& Saif, 2003); and nF, GTCGACGGYCTKGTSTTCCT; nR, CACAGCGACAAATCATGAAA (Park et al., 2006)) targeting the $R d R p$ gene were used with the following reaction conditions: $94^{\circ} \mathrm{C}$ for 5 min, followed by 35 cycles at $94^{\circ} \mathrm{C}$ for $30 \mathrm{~s}, 54^{\circ} \mathrm{C}$ for $30 \mathrm{~s}$ and $72^{\circ} \mathrm{C}$ for $40 \mathrm{~s}$, with a final extension at $72^{\circ} \mathrm{C}$ for $10 \mathrm{~min}$. The reaction generated a $326 \mathrm{bp}$ PCR product. In addition, three other diarrhea-related enteric viruses, i.e., bovine viral diarrhea virus, bovine rotavirus, and bovine coronavirus, were detected using previously reported molecular methods for the evaluation of possible co-infection with BNoV.

\section{Sequencing and phylogenetic analysis of the complete genome of the $\mathrm{Bo} / \mathrm{CH} / \mathrm{HB} / \mathrm{BD} / 2019$} strain

Based on the GenBank sequences, we designed six pairs of specific primers using Primer Premier 5 software. The reference sequences were AY126472.2, JX145650.1, EU794907, AF097917.5, MK159169.1 and NC_029645.1. The complete BNoV genome of the strain Bo/CH/HB/BD/2019 was amplified using six sequencespecific primer pairs.

Reactions were performed in a total volume of $20 \mu \mathrm{L}(2 \mu \mathrm{L}$ of cDNA, $2 \mu \mathrm{L}$ of $10 \times$ PCR Buffer, $3 \mu \mathrm{L}$ of $2.5 \mathrm{mM}$ dNTP, $1 \mu \mathrm{L}$ of each primer, $0.5 \mu \mathrm{L}$ of Taq polymerase, and $10 \mu \mathrm{L}$ of $\mathrm{ddH}_{2} \mathrm{O}$ ). The whole genome of $\mathrm{BNoV}$ strain Bo/CH/HB/BD/2019 was amplified by RT-PCR (oligonucleotide primers are presented in Table 1). All PCR products were purified with the PCR Purification Miniprep Kit (BIOMIGA, Shanghai, China) following the manufacturer's instructions. The PCR products were cloned into the pMD19-T cloning vector (TaKaRa Biotechnology, Dalian, China). The positive recombinant plasmids were verified by restriction enzyme digestion and sequenced by Sangon Biotech (Beijing, China). The raw genomic sequence fragments were imported to SeqMan in DNAStar (DNAStar, Inc., Madison, WI, USA) for assembly and annotation. The complete BNoV genome sequence has been deposited in GenBank (accession number: MN480761). Sequencing and phylogenetic analysis of the complete genome of the $\mathrm{Bo} / \mathrm{CH} / \mathrm{HB} / \mathrm{BD} / 2019$ strain was performed using the Clustal W program in DNA Star software. Then, 10,000 bootstrap replication was performed using MEGA 7 software, and the phylogenetic tree was constructed by the neighbor-joining method.

\begin{tabular}{llll}
\hline Primer & Sequence (5'-3') & Product size(bp) & Annealing temperature () \\
\hline BNoV1F & TGAATGAAGACTTTGACG & 1465 & 52 \\
BNoV1R & CGCACCCGATTAGACAT & & \\
BNoV2F & CCTCGGKCARTATGGDA & 1304 & 53 \\
BNoV2R & CTTGGATGGCAGTGGTH & & \\
BNoV3F & TGTGACCACTGCCATCCA & 1638 & 52 \\
BNoV3R & GCCACCAGCTCATCCTT & & \\
BNoV4F & TCCCTGGACAAAACTACC & 1151 & 49
\end{tabular}




\begin{tabular}{llll}
\hline Primer & Sequence (5'-3') & Product size(bp) & Annealing temperature () \\
\hline BNoV4R & CCTTCCCACAGTGACAGAT & & \\
BNoV5F & GAYGAYCCGARYGARAC & 1563 & 49 \\
BNoV5R & GAAACGAAATGGGTAATC & & \\
BNoV6F & GATTACCCATTTBGTYTC & 924 & 42 \\
BNoV6R & AACACTGCTCACTATTTC & & \\
\hline
\end{tabular}

\section{Results and discussion}

BNoV has been detected in many countries. This disease was first detected in China in 2018, and has been reported in central and southern China. Here, we detected a new BNoV strain, named Bo/CH/HB/BD/2019 (GenBank accession number: MN480761), in Hebei, in northern China, and sequenced its whole genome. We collected 39 samples, two (5.1\%) of which were $\mathrm{BNoV}$ positive. One sample was co-infected with bovine rotavirus. The BNoV detection rate was similar to those reported in Belgium (7.5\%) (Mauroy et al., 2009), Argentina, (3.3 \%) (Ferragut et al., 2016), and South Korea (2.8\%) (Park et al., 2008), and much lower than those reported in the USA (72.1\%) (Smiley,Hoet,Traven,Tsunemitsu, \& Saif, 2003), Norway (49.6\%) (Jor,Myrmel, \& Jonassen, 2010b) and Iran (39.5\%) (Pourasgari et al., 2018), and also lower than those reported in central China (25\%) and south China (20.4\%) (Shi,Wang,Xu,Zhang, \& Lan, 2019; Wang,Yue, \& Tang, 2019). Although it has been confirmed that BNoV is prevalent in China, few studies and epidemiological data are available on $\mathrm{BNoV}$ in China.

We sequenced and analyzed the $\mathrm{Bo} / \mathrm{CH} / \mathrm{HB} / \mathrm{BD} / 2019$ genome, and learned that its genome is $7320 \mathrm{nu}-$ cleotides (nt) and includes three ORFs, a 21 nt 5' untranslated region, and a 49 nt 3' untranslated region. ORF1 is located from 22 nt to 5076 nt and encodes a 1685 aa non-structural protein. ORF2 is located from $5063 \mathrm{nt}$ to $6631 \mathrm{nt}$ and encodes the 523 aa VP1 protein. ORF3 is located from 6621 nt to $7271 \mathrm{nt}$ and encodes the 217 aa VP2protein. ORF1, ORF2, and ORF3 overlap each other by 14 nt and 11 nt. Based on the complete BNoV sequences available in the GenBank database, we compared the isolated strain $\mathrm{Bo} / \mathrm{CH} / \mathrm{HB} / \mathrm{BD} / 2019$ with seven isolates from other regions of the world. The sequence similarity between $\mathrm{Bo} / \mathrm{CH} / \mathrm{HB} / \mathrm{BD} / 2019$ and the other isolates ranged from $84.0-92.4 \%$. The homology between the isolates and all complete sequences in the GenBank database ranged from $69.9 \%$ to $91.8 \%$ for VP1 and from $67.9 \%$ to $91.2 \%$ for $V P^{2}$ (Table 2), indicating that $\mathrm{BNoV}$ genes are diverse and hence require further exploration.

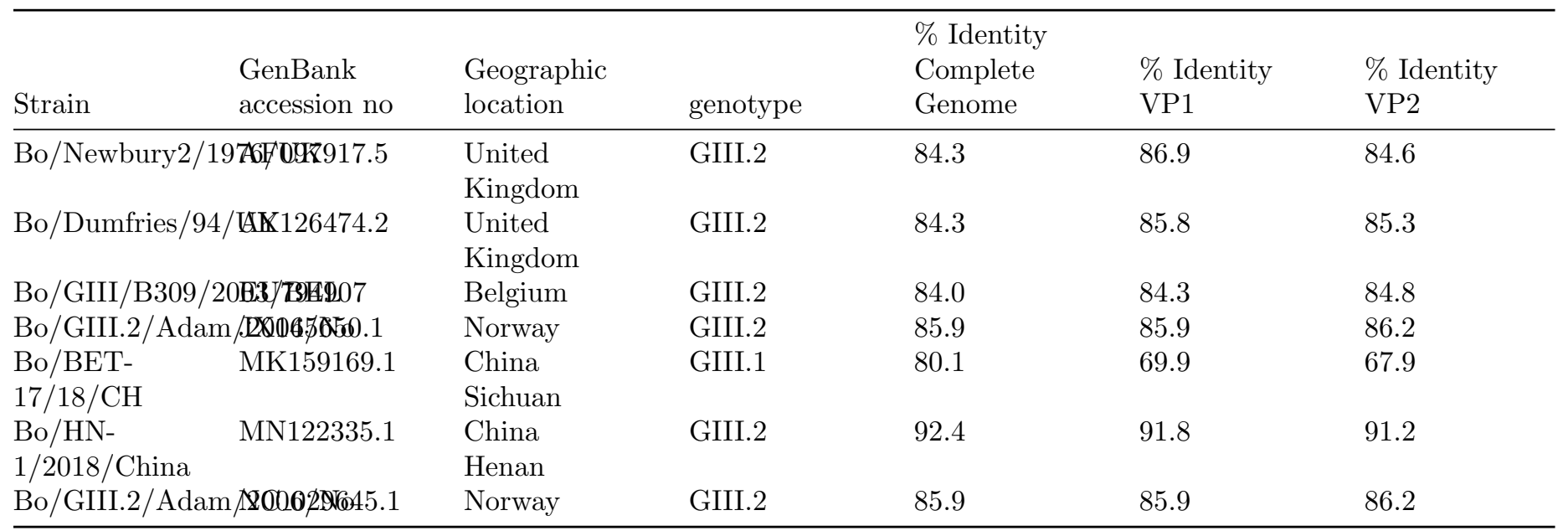




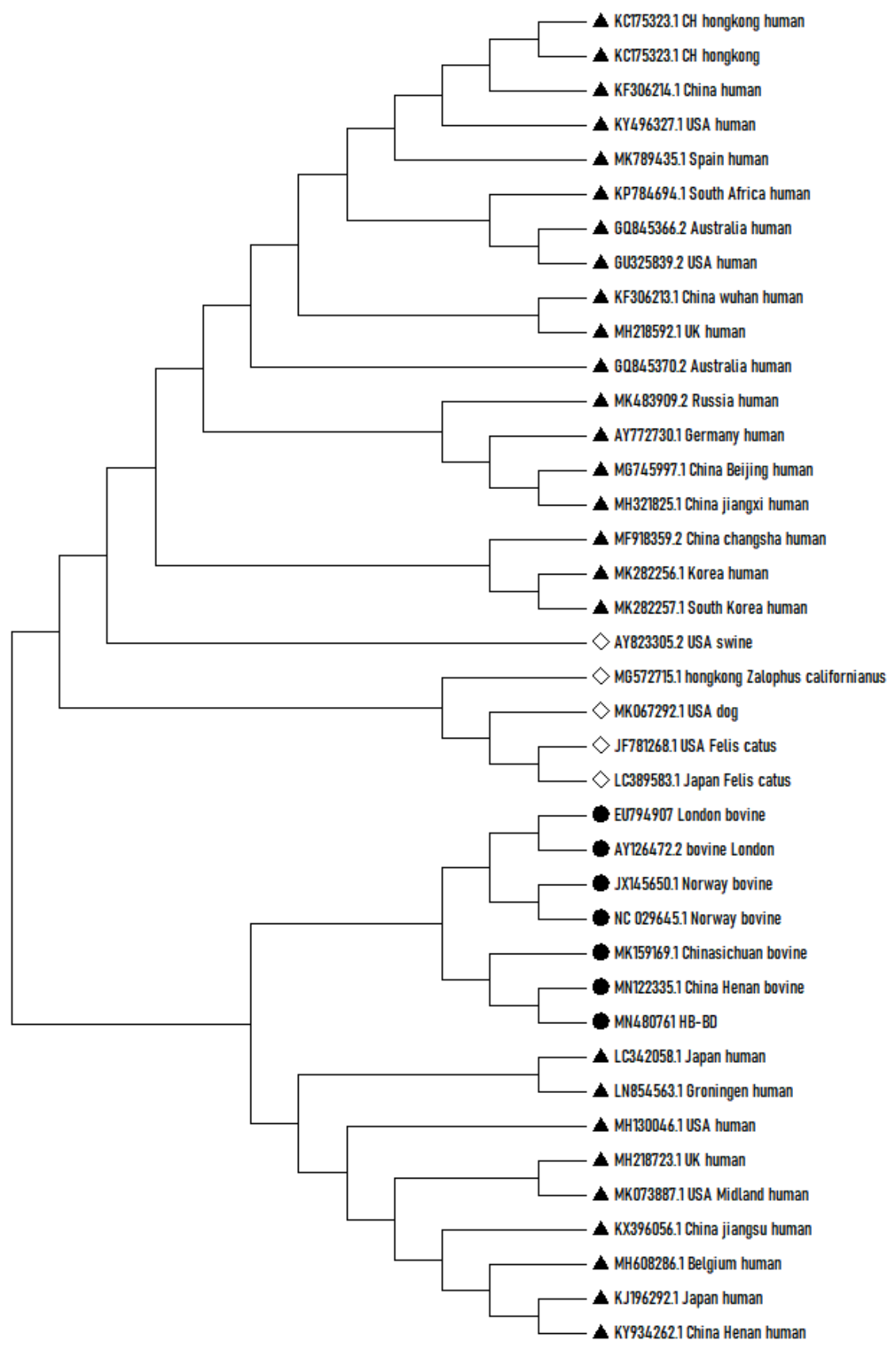

Phylogenetic trees of different hosts and genotypes were constructed based on the complete Bo/CH/HB/BD/2019 genome sequence and the complete genomes in the GenBank database (Figure 1). Figure 1a shows that bovine isolates and human isolates are far related, so there is no potential risk of cross-infection at present. However, BNoV (GIII) serum antibodies have been detected in humans (Widdowson et al., 2005) and human NoV sequences have been detected in bovine fecal samples (Menon et al., 2013), and interspecific transmission may occur in the future. Figure $1 \mathrm{~b}$ shows that all $\mathrm{BNoV}$ isolates belonged to the GIII genotype. The $\mathrm{Bo} / \mathrm{CH} / \mathrm{HB} / \mathrm{BD} / 2019$ strain is more closely related to the other two Chinese strains than to those from other countries, and is hence clustered in the Chinese $\mathrm{BNoV}$ branch in the phylogenetic tree. The isolated strain 
was more closely related to the Bo/HN-1/2018/China strain from Henan (central China) (GenBank accession number: MN122335.1) than to the Bo/BET-17/18/CH strain from Sichuan (southern China) (GenBank accession number: MK159169.1). This suggests that there may be a different evolutionary process underlying the spread of BNoV in China. Unfortunately, few data are available on the genetic evolution and prevalence of BNoV in China.

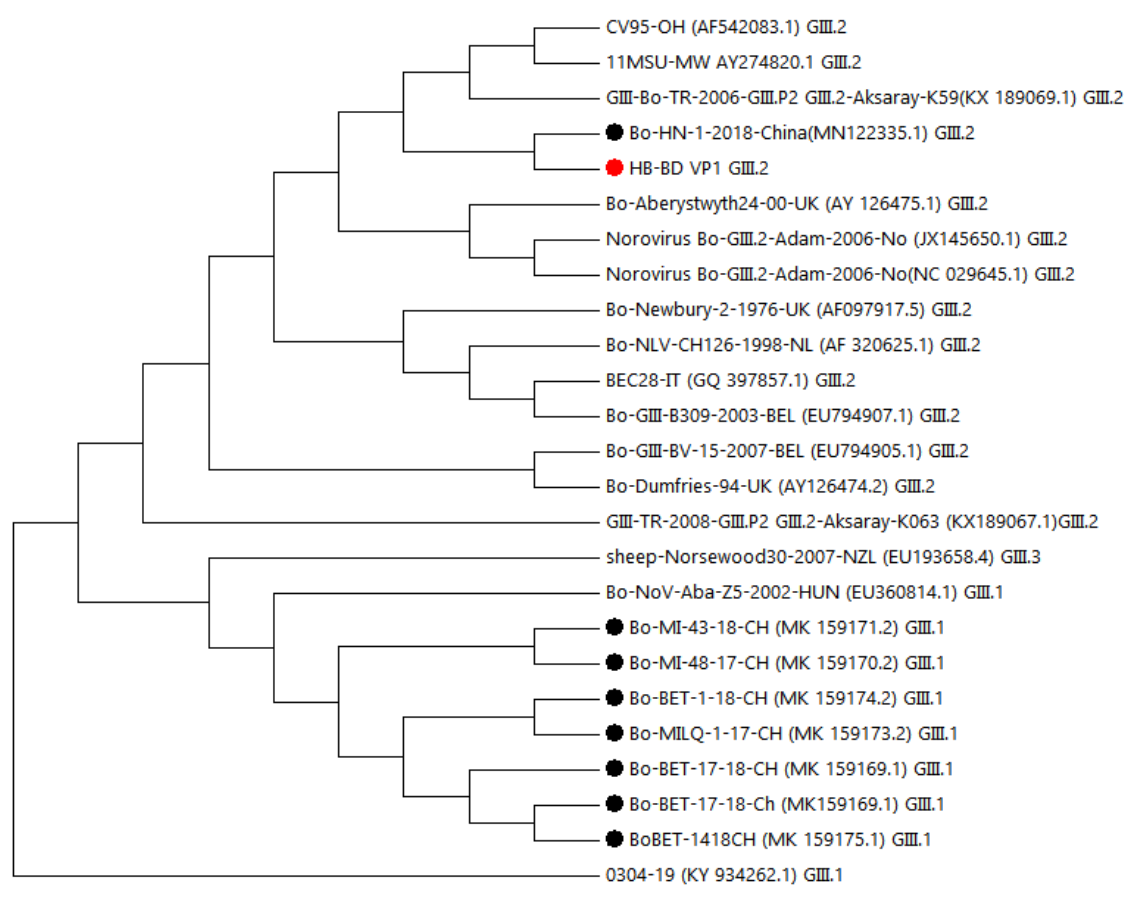

The BNoV RdRp gene contains highly conserved regions. VP1 is the major structural component of caliciviruses and is involved in receptor recognition, host specificity, strain antigenic diversity, and immunogenicity (Chen et al., 2004). VP2 is highly variable and can contain different types of mutations (Bok et al., 2009; Seah,Gunesekere,Marshall, \& Wright, 1999). VP2 interacts with VP1 and, in turn, enhances the expression of capsid proteins (Vongpunsawad,Venkataram, \& Estes, 2013). Due to the slightly different topologies between ORF2 and ORF3, different BNoV VP2 gene may have resulted from distinct evolutionary strategies (Kamel et al., 2009). Phylogenetic trees were constructed based on the BNoV VP1 and RdRp genes (Figure 2). The strain isolated in the present study and CH-HNSC-2018 were clustered in one branch, while strains isolated from Sichuan, southern China, were clustered in another branch, indicating that the BNoV strains in China are diverse. Different strains with different genotypes exist in China, making the prevention and control of viral spread difficult (Figure 2a). The sequence and phylogenetic analyses showed that Bo/CH/HB/BD/2019 belongs to GIII.2 BNoV (Figure 2b).

The VP1 protein includes a shell $(\mathrm{S})$ domain, which is highly conserved among different NoVs, and a protruding (P) domain, with N-terminal P1 and C-terminal P1 and P2 parts (Chen et al., 2013). The highly variable region of the sequence (residues 279-406) forms the externally located P2 subdomain, whereas the central subdomain P1 (residues 226-278 and the C-terminal 124 residues) is located between the S and P2 domains (Venkataram,Hardy, \& Estes, 2000). Comparing with previous studies, in both China and other countries, we found four new aa substitutions in VP1 , i.e., 225C, 246T, $624 \mathrm{~T}$, and $945 \mathrm{~T}$. The $225 \mathrm{C}$ residue is located in the conserved region and $246 \mathrm{~T}$ is located in the P1 subdomain in the highly variable region. This may be an adaptation that is unique to $\mathrm{BNoV}$ circulating in cattle farms in Hebei, China. Whether these mutations in $\mathrm{Bo} / \mathrm{CH} / \mathrm{HB} / \mathrm{BD} / 2019$ lead to changes in virulence, pathogenicity, and antigenicity remains to be explored. 
In conclusion, in this study we isolated the $\mathrm{Bo} / \mathrm{CH} / \mathrm{HB} / \mathrm{BD} / 2019$ strain from Hebei, sequenced its genome, and identified its genes. We analyzed its sequence homology with other BNoV strains and constructed phylogenetic trees to analyze its genetic evolution. Our results provide a reference for the development of a BNoV vaccine to prevent and control viral spread. Nevertheless, more data are still required, so in the future it will be necessary to further monitor and research BNoV and its subtypes.

\section{Acknowledgments}

This research was supported by the Program of the Modern Agriculture Industry Technology System Foundation of Hebei Province (HBCT2018120406, HBCT2018130405) and the Hebei Key Research and Development Program (19226611D).

\section{Conflict of interest}

The authors declare no conflict of interest.

\section{Ethical statement}

The authors confirm that the ethical policies of the journal, as noted on the journal's author guidelines page, have been adhered to and the appropriate ethical review committee approval has been received. The US National Research Council's guidelines for the Care and Use of Laboratory Animals were followed.

\section{All data generated or analyzed during this study are included in this article.}

\section{References:}

Bok, K., Abente, E. J., Realpe-Quintero, M., Mitra, T., Sosnovtsev, S. V., Kapikian, A. Z.,... Green, K. Y. (2009). Evolutionary dynamics of GII.4 noroviruses over a 34-year period. Journal of Virology,83(22), 11890-11901.doi:10.1128/JVI.00864-09

Bridger, J. C., Hall, G. A., \& Brown, J. F. (1984). Characterization of a calici-like virus (Newbury agent) found in association with astrovirus in bovine diarrhea. Infection and Immunity, 43(1),133-138

Chen, L., Wu, D., Ji, L., Wu, X., Xu, D., Cao, Z.,... Han, J. (2013). Bioinformatics analysis of the epitope regions for norovirus capsid protein. Bmc Bioinformatics, 14 Suppl 4,S5.doi:10.1186/1471-2105-14-S4-S5

Chen, R., Neill, J. D., Noel, J. S., Hutson, A. M., Glass, R. I., Estes, M. K.,.. . Prasad, B. V. (2004). Interand intragenus structural variations in caliciviruses and their functional implications. Journal of Virology, 78(12),6469-6479.doi:10.1128/JVI.78.12.6469-6479.2004

Cho, Y. I., Han, J. I., Wang, C., Cooper, V., Schwartz, K., Engelken, T.,... Yoon, K. J. (2013). Casecontrol study of microbiological etiology associated with calf diarrhea. Veterinary Microbiology,166(3-4), 375-385.doi:10.1016/j.vetmic.2013.07.001

Deval, J., Jin, Z., Chuang, Y. C., \& Kao, C. C. (2017). Structure(s), function(s), and inhibition of the RNAdependent RNA polymerase of noroviruses. Virus Research, 234,21-33.doi:10.1016/j.virusres.2016.12.018

Ferragut, F., Vega, C. G., Mauroy, A., Conceicao-Neto, N., Zeller, M., Heylen, E.,... Parreno, V. (2016). Molecular detection of bovine Noroviruses in Argentinean dairy calves: Circulation of a tentative new genotype. Infection Genetics and Evolution, 40,144-150.doi:10.1016/j.meegid.2016.02.034

Gunther, H., Otto, P., \& Heilmann, P. (1984). [Diarrhea in young calves. 6. Determination of the pathogenicity of a bovine coronavirus and an unidentified icosahedral virus]. Arch Exp Veterinarmed,38(5), 781-792

Hassine-Zaafrane, M., Kaplon, J., Sdiri-Loulizi, K., Aouni, Z., Pothier, P., Aouni, M.,.. A Ambert-Balay, K. (2012). Molecular prevalence of bovine noroviruses and neboviruses detected in central-eastern Tunisia.Archives of Virology, 157(8),1599-1604.doi:10.1007/s00705-012-1344-5

Jor, E., Myrmel, M., \& Jonassen, C. M. (2010a). SYBR Green based real-time RT-PCR assay for detection and genotype prediction of bovine noroviruses and assessment of clinical significance in Norway. Journal of 
Virological Methods, 169(1),1-7.doi:10.1016/j.jviromet.2010.03.028

Jor, E., Myrmel, M., \& Jonassen, C. M. (2010b). SYBR Green based real-time RT-PCR assay for detection and genotype prediction of bovine noroviruses and assessment of clinical significance in Norway. Journal of Virological Methods, 169(1),1-7.doi:10.1016/j.jviromet.2010.03.028

Jung, K., Scheuer, K. A., Zhang, Z., Wang, Q., \& Saif, L. J. (2014). Pathogenesis of GIII.2 bovine norovirus, CV186-OH/00/US strain in gnotobiotic calves. Veterinary Microbiology, 168(1),202-207.doi:10.1016/j.vetmic.2013.11.008

Kamel, A. H., Ali, M. A., El-Nady, H. G., de Rougemont, A., Pothier, P., \& Belliot, G. (2009). Predominance and circulation of enteric viruses in the region of Greater Cairo, Egypt. Journal of Clinical Microbiology, 47(4), 1037-1045.doi:10.1128/JCM.01381-08

Kaplon, J., Guenau, E., Asdrubal, P., Pothier, P., \& Ambert-Balay, K. (2011). Possible novel nebovirus genotype in cattle, France. Emerging Infectious Diseases, 17(6),1120-1123.doi:10.3201/eid/1706.100038

Lee, J. H., Chung, M. S., \& Kim, K. H. (2017). Structure and Function of Caliciviral RNA Polymerases. Viruses, 9(11).doi:10.3390/v9110329

Lin, Y., Fengling, L., Lianzhu, W., Yuxiu, Z., \& Yanhua, J. (2014). Function of VP2 protein in the stability of the secondary structure of virus-like particles of genogroup II norovirus at different $\mathrm{pH}$ levels: function of VP2 protein in the stability of NoV VLPs. Journal of Microbiology, 52(11), 970-975.doi:10.1007/s12275$014-4323-6$

Lindesmith, L. C., Costantini, V., Swanstrom, J., Debbink, K., Donaldson, E. F., Vinje, J.,.. Baric, R. S. (2013). Emergence of a norovirus GII.4 strain correlates with changes in evolving blockade epitopes. Journal of Virology, 87(5),2803-2813.doi:10.1128/JVI.03106-12

Lochridge, V. P., \& Hardy, M. E. (2007). A single-amino-acid substitution in the P2 domain of VP1 of murine norovirus is sufficient for escape from antibody neutralization. Journal of Virology, 81(22),1231612322.doi:10.1128/JVI.01254-07

Mauroy, A., Scipioni, A., Mathijs, E., Saegerman, C., Mast, J., Bridger, J. C.,... Thiry, E. (2009). Epidemiological study of bovine norovirus infection by RT-PCR and a VLP-based antibody ELISA. Veterinary Microbiology, 137(3-4),243-251.doi:10.1016/j.vetmic.2009.01.031

Menon, V. K., George, S., Shanti, A. A., Saravanabavan, A., Samuel, P., Ramani, S.,... Kang, G. (2013). Exposure to human and bovine noroviruses in a birth cohort in southern India from 2002 to 2006. Journal of Clinical Microbiology, 51(7),2391-2395.doi:10.1128/JCM.01015-13

Otto, P. H., Clarke, I. N., Lambden, P. R., Salim, O., Reetz, J., \& Liebler-Tenorio, E. M. (2011). Infection of calves with bovine norovirus GIII.1 strain Jena virus: an experimental model to study the pathogenesis of norovirus infection. Journal of Virology,85(22), 12013-12021.doi:10.1128/JVI.05342-11

Park, S. I., Jeong, C., Kim, H. H., Park, S. H., Park, S. J., Hyun, B. H.,. . Cho, K. O. (2007). Molecular epidemiology of bovine noroviruses in South Korea. Veterinary Microbiology, 124(1-2),125-133.doi:10.1016/j.vetmic.2007.03.010

Park, S. I., Jeong, C., Park, S. J., Kim, H. H., Jeong, Y. J., Hyun, B. H.,... Cho, K. O. (2008). Molecular detection and characterization of unclassified bovine enteric caliciviruses in South Korea. Veterinary Microbiology, 130(3-4),371-379.doi:10.1016/j.vetmic.2008.01.017

Park, S. J., Jeong, C., Yoon, S. S., Choy, H. E., Saif, L. J., Park, S. H.,... Cho, K. O. (2006). Detection and characterization of bovine coronaviruses in fecal specimens of adult cattle with diarrhea during the warmer seasons. Journal of Clinical Microbiology,44(9), 3178-3188.doi:10.1128/JCM.02667-05

Pourasgari, F., Kaplon, J., Sanchooli, A., Fremy, C., Karimi-Naghlani, S., Otarod, V.,... Pothier, P. (2018). Molecular prevalence of bovine noroviruses and neboviruses in newborn calves in Iran. Archives of Virology,163(5), 1271-1277.doi:10.1007/s00705-018-3716-y 
Seah, E. L., Gunesekere, I. C., Marshall, J. A., \& Wright, P. J. (1999). Variation in ORF3 of genogroup 2 Norwalk-like viruses.Archives of Virology, 144(5),1007-1014.doi:10.1007/s007050050563

Shi, Z., Wang, W., Xu, Z., Zhang, X., \& Lan, Y. (2019). Genetic and phylogenetic analyses of the first GIII.2 bovine norovirus in China.BMC Veterinary Research, 15(1),311.doi:10.1186/s12917-019-2060-0

Smiley, J. R., Chang, K. O., Hayes, J., Vinje, J., \& Saif, L. J. (2002). Characterization of an enteropathogenic bovine calicivirus representing a potentially new calicivirus genus. Journal of Virology, 76(20),1008910098.doi:10.1128/jvi.76.20.10089-10098.2002

Smiley, J. R., Hoet, A. E., Traven, M., Tsunemitsu, H., \& Saif, L. J. (2003). Reverse transcription-PCR assays for detection of bovine enteric caliciviruses (BEC) and analysis of the genetic relationships among BEC and human caliciviruses. Journal of Clinical Microbiology,41(7), 3089-3099.doi:10.1128/jcm.41.7.30893099.2003

van der Poel, W. H., van der Heide, R., Verschoor, F., Gelderblom, H., Vinje, J., \& Koopmans, M. P. (2003). Epidemiology of Norwalk-like virus infections in cattle in The Netherlands. Veterinary Microbiology,92(4), 297-309.doi:10.1016/s0378-1135(02)00421-2

van Der Poel, W. H., Vinje, J., van Der Heide, R., Herrera, M. I., Vivo, A., \& Koopmans, M. P. (2000). Norwalk-like calicivirus genes in farm animals. Emerging Infectious Diseases, 6(1),36-41.doi:10.3201/eid0601.000106

Venkataram, P. B., Hardy, M. E., \& Estes, M. K. (2000). Structural studies of recombinant Norwalk capsids. Journal of Infectious Diseases, 181 Suppl 2, S317-S321.doi:10.1086/315576

Vongpunsawad, S., Venkataram, P. B., \& Estes, M. K. (2013). Norwalk Virus Minor Capsid Protein VP2 Associates within the VP1 Shell Domain.Journal of Virology, 87(9),4818-4825.doi:10.1128/JVI.03508-12

Wang, Y., Yue, H., \& Tang, C. (2019). Prevalence and complete genome of bovine norovirus with novel VP1 genotype in calves in China. Sci Rep, 9(1), 12023.doi:10.1038/s41598-019-48569-4

Widdowson, M. A., Rockx, B., Schepp, R., van der Poel, W. H., Vinje, J., van Duynhoven, Y. T.,... Koopmans, M. P. (2005). Detection of serum antibodies to bovine norovirus in veterinarians and the general population in the Netherlands. Journal of Medical Virology,76(1), 119-128.doi:10.1002/jmv.20333

Wise, A. G., Monroe, S. S., Hanson, L. E., Grooms, D. L., Sockett, D., \& Maes, R. K. (2004). Molecular characterization of noroviruses detected in diarrheic stools of Michigan and Wisconsin dairy calves: circulation of two distinct subgroups. Virus Research,100(2), 165-177.doi:10.1016/j.virusres.2003.11.014

Wolf, S., Williamson, W. M., Hewitt, J., Rivera-Aban, M., Lin, S., Ball, A.,. . Greening, G. E. (2007). Sensitive multiplex real-time reverse transcription-PCR assay for the detection of human and animal noroviruses in clinical and environmental samples. Appl Environ Microbiol, 73(17), 5464-5470.doi:10.1128/AEM.0057207

Woode, G. N., \& Bridger, J. C. (1978). Isolation of small viruses resembling astroviruses and caliciviruses from acute enteritis of calves. Journal of Medical Microbiology, 11(4),441-452.doi:10.1099/00222615-11-4-441 

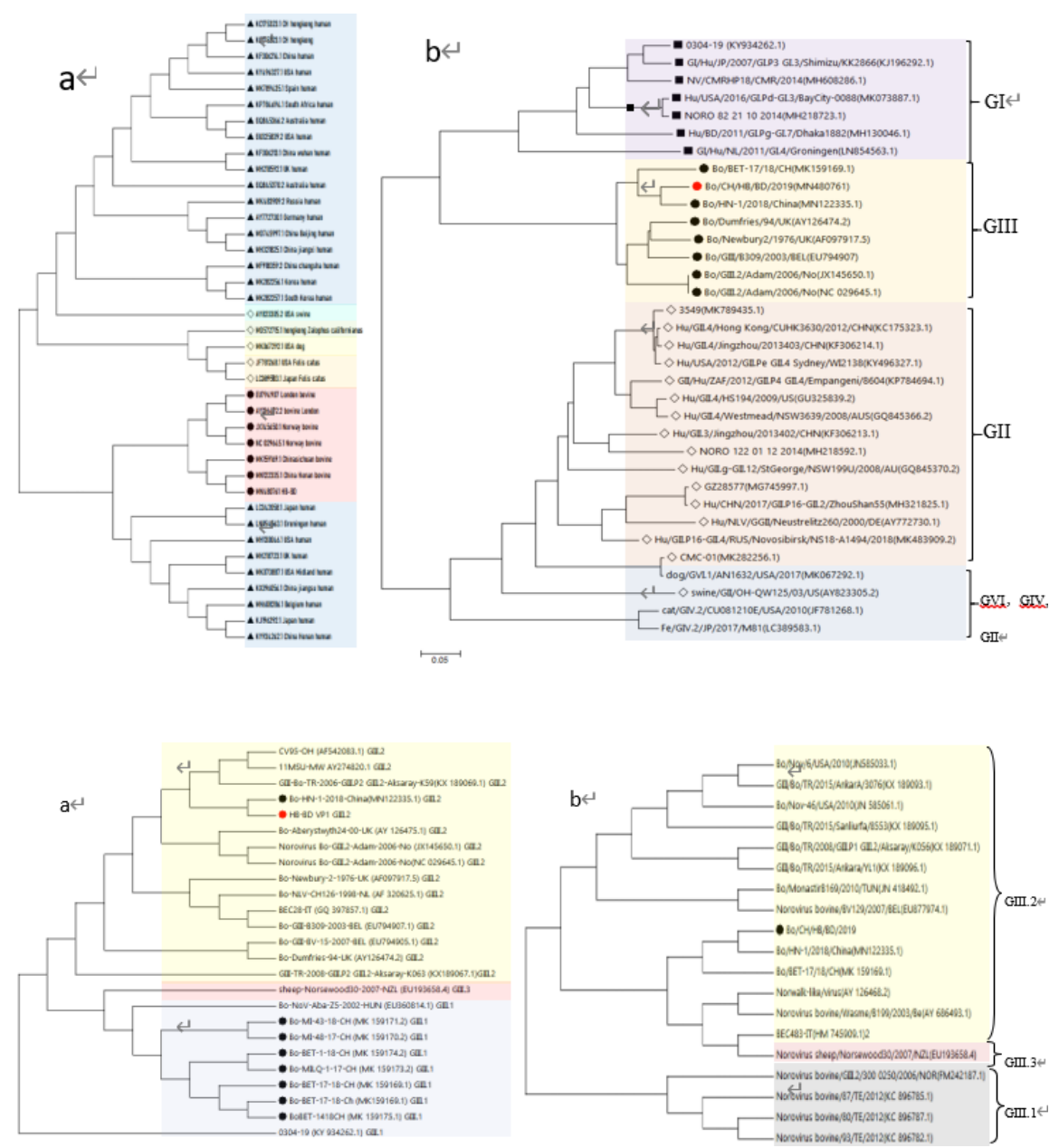

\section{Hosted file}

Table1. docx available at https : //authorea.com/users/313825/articles/444254-complete-genome-andsequence-and-phylogenetic-analyses-of-the-first-bovine-norovirus-strain-identified-in-northernchina

\section{Hosted file}

Table2. docx available at https://authorea.com/users/313825/articles/444254-complete-genome-andsequence-and-phylogenetic-analyses-of-the-first-bovine-norovirus-strain-identified-in-northernchina 